\title{
A Retrospective Evaluation of Bevacizumab Treatment in Patients with Progressive Malignant Glioma in Northern Sweden
}

\author{
MARIA SANDSTRÖM ${ }^{1}$, MARIA LAUDIUS ${ }^{1}$, THOMAS LINDQVIST ${ }^{2}$, \\ THOMAS ASKLUND ${ }^{1}$ and MIKAEL JOHANSSON ${ }^{1}$ \\ ${ }^{1}$ Department of Radiation Sciences, Oncology Umea University, Umea, Sweden; \\ ${ }^{2}$ Department of Radiation Sciences, Radiology Umea University, Umea, Sweden
}

\begin{abstract}
Background/Aim: Overall survival for glioblastoma patients is short. Standard treatment is surgery followed by radiochemotherapy and adjuvant temozolomide. The aim of this study was to evaluate the outcome for all patients with progressive disease treated with bevacizumabbased treatment combinations in the northern region of Sweden. Patients and Methods: This was a single-center retrospective analysis after bevacizumab-based second-line treatment for malignant glioma. All patients treated with bevacizumab, between 2007 and 2011 in our Center were retrospectively evaluated. Results: Progression-free survival after the start of bevacizumab-based treatment was 20 weeks and overall survival was 31 weeks. Treatment was well tolerated, but $9 \%$ of patients $(n=6)$ suffered from serious adverse events. In $68 \%$ of patients, $a \geq 25 \%$ decrease in contrast enhancement was seen at best response. Conclusion: Results from this retrospective study are comparable with earlier phase-II studies and motivate randomized trials of bevacizumab-based treatment in the second-line setting.
\end{abstract}

Malignant glioma is a disease still associated with poor prognosis despite current treatment strategies, including surgical resection or biopsy followed by radiotherapy and/or chemotherapy. The disease often affects cognitive and emotional skills, and is often associated with changes in personality that results in additional stress for patients and their carers. The present first-line treatment for glioblastoma was established after a pivotal study, showing that

Correspondence to: Maria Sandström, Department of Radiation Sciences, Oncology, Umeå University, S-901 85 Umeå, Sweden. Tel: +46907850000, Fax: +46907852031, e-mail: maria.sandstrom@umu.se

Key Words: Malignant glioma, bevacizumab, anti-angionenesis treatment. radiotherapy concomitant with chemotherapy followed by adjuvant chemotherapy prolonged median survival from 12.1 to 14.6 months compared to treatment with radiotherapy alone (1). The later reported 5 year follow-up of this study showed that $10 \%$ of the patients treated with radiochemotherapy were alive compared to $2 \%$ in the group of patients treated with radiotherapy only (2). However, recent evaluation of the Swedish population based brain tumour registry shows a significantly shorter median overall survival of 10.5 months, reflecting the prognosis in an unselected group of patients (3).

Despite aggressive treatment most patients experience relapse of their disease and besides surgery and retreatment with temozolomide there is no consensus on second-line treatment for recurrent disease. There exist few treatments to choose from and those include CCNU in monotherapy or in combination with procarbazine and vincristine (PCV). These therapies have many side-effects and only moderate effects on the disease progression.

During the last decade, anti-angiogenic therapy to treat cancer has been established. Tumour angiogenesis is a multistep cellular process involving many different mechanisms. In the angiogenic cascade, vascular endothelial growth factor (VEGF) has been identified as one of the most important molecules and is highly up-regulated in glioblastoma (4). Brain tumour cells may acquire access to blood supply by different mechanisms. Sprouting angiogenesis, vascular cooption and myeloid cell-derived angiogenesis have support from preclinical models whereas the role for other mechanisms as vascular intussusception, vasculogenic mimicry, bone marrow-derived vasculogenesis and cancer stem-like cell-derived vasculogenesis are more controversial today in glioma (4).

Anti-angiogenic-treatment has now been introduced in the second-line setting for malignant glioma. In 2007, the first study on treatment of progressive malignant glioma with the anti-VEGF MAb bevacizumab and the topoisomerase-1 
inhibitor irinotecan was published (5). This study was a phaseII study on 32 patients with progressive malignant glioma. Radiologic response was seen in $63 \%$ of the patients with a progression free survival and median overall survival of 23 weeks and 40 weeks, respectively, from treatment start. Concerning the role of bevacizumab for treatment of malignant gliomas many studies have been published after the study by Vredenburg et al. 2007. Several studies demonstrated an improvement of quality of life and patient independence and acceptable side-effects in patients treated with bevacizumab (5-8). The recently published randomized phaseII BELOB-study indicates that bevacizumab in combination with chemotherapy is more effective than bevacizumab in monotherapy (9).

The aim of this retrospective study was to evaluate all patients with progressive malignant glioma that had been treated with different bevacizumab-based treatment combinations in the northern region of Sweden, focusing on response and side-effects.

\section{Patients and Methods}

Patients with malignant glioma treated with bevacizumab at relapse or progression following standard treatment with radiochemotherapy after surgical resection or biopsy between 2007 and 2011 in northern Sweden were included in this retrospective cohort study. Clinical parameters were collected from medical records. Inclusion criteria were; glioma grade III-IV, initial postoperative treatment with radio-chemotherapy according to standard protocols, MRI evidence of tumour recurrence after this treatment, and treatment with bevacizumab based combinations after recurrence/progressive disease. The study was approved by the regional ethical review board (Dnr 2013-35-31M).

Of the 67 patients identified from the medical records, three were excluded due to initial misdiagnosis: one patient with neurofibroma, one patient with an atypical meningioma and one patient with a leptomeningial sarcoma. Five patients were not initially treated with radio-chemotherapy and therefore excluded from the evaluation. Ten patients were treated with bevacizumab in first line (three of those fulfilled both above mentioned exclusion criteria) and therefore excluded from this study. The study thus included 52 patients. Patient characteristics are presented in Table I.

Tumour volume was defined as total volume of contrastenhancing tumour component including central necrotic tumour components when present. Measurement of tumour volume was performed manually by a trained operator using the area measurement tool in a regular PACS workstation (Sectra Workstation IDS7, Sectra AB, Linköping, Sweden). The image material consisted mainly of three-dimensional T1-weighted gradient echo images acquired after administration of gadolinium contrast medium and reformatted in three orthogonal planes with 1 $\mathrm{mm}$ or $3 \mathrm{~mm}$ thick sections without intersection gap. In a few cases the images were contrast enhanced $\mathrm{T} 1$-weighted spin echo images with $5 \mathrm{~mm}$ sections and $1 \mathrm{~mm}$ intersection gap. Also, some CT examinations were included, consisting of contrast-enhanced images with $3 \mathrm{~mm}$ or $5 \mathrm{~mm}$ slice thickness. The outer contour of the enhancing tumour was traced manually with the area measurement
Table I. Patient characteristics.

\begin{tabular}{lcc}
\hline Variable & $\mathrm{N}=52$ & $\%$ \\
\hline Age & & \\
$\quad$ Median (range) & $56(31-76)$ & \\
Gender & 33 & 63 \\
$\quad$ Male & 19 & 37 \\
Female & & \\
Surgery performed & 12 & 23 \\
Biopsy & 30 & 58 \\
Partial resection & 10 & 19 \\
Gross total resection & & \\
Diagnosis & 10 & 19 \\
WHO grade III & 42 & 81 \\
WHO grade IV & & \\
Chemotherapy line & 45 & 87 \\
2 line & 7 & 13 \\
3 line & $11(1-28)$ & \\
Number of treatments with bevacizumab & \\
$\quad$ Median (range) & 4 & 8 \\
WHO Performance Status & 22 & 42 \\
0 & 16 & 31 \\
1 & 10 & 19 \\
2 & & \\
3 &
\end{tabular}

tool in each section containing enhancing tumour, the area was multiplied with the section thickness to calculate a per section tumour volume. The total tumour volume was then obtained by adding the volumes for all tumour-containing sections. Eight patients were not evaluable on radiological examination.

Clinical and radiographic data was collected in a MS Excel spreadsheet (Microsoft Redmond, WA, USA) and descriptive as well as survival statistics and hypothesis testing was done in SPSS statistics 21 (IBM, Armonk, NY, USA). Survival analysis was done using Kaplan-Mayer plots and hypothesis testing was performed using the log-rank test.

\section{Results}

Out of 52 patients analyzed according to the inclusion criteria, 33 were males and 19 were females. Forty patients underwent tumour resection and 12 had a stereotactic biopsy before treatment. Most patients were treated with bevacizumab $10 \mathrm{mg} / \mathrm{kg}$ as start dose and then either continued with the same dose (15 patients) or continued with $5 \mathrm{mg} / \mathrm{kg}$ (34 patients). Three patients received only one dose of bevacizumab. In most cases bevacizumab was combined with irinotecan or temozolomide. Patients were treated with a median 11 cycles of bevacizumab (range=1-28 cycles). Forty-two patients were diagnosed with glioblastoma and 10 patients with anaplastic glioma WHO grade III. Forty-two of the patients were of performance status (PS) $0-2$ but 10 were of PS status 3 . Of the 52 treated patients, 45 were treated in second line and 7 in third line (Table I). 

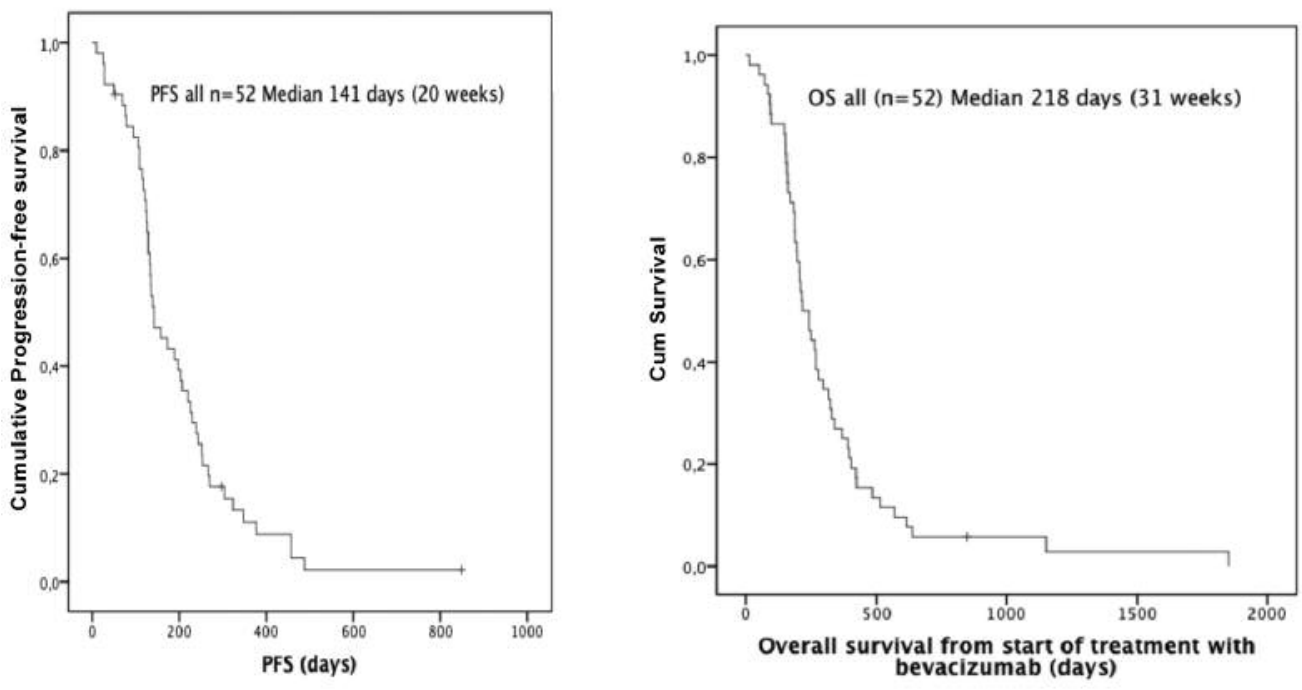

$\underset{+ \text { Censored }}{\stackrel{\text { Surval }}{+} \text { function }}$

Figure 1. PFS and OS in all patients. Median PFS was 141 days (95\%CI=96-185), representing 20 weeks and median OS was 218 days (95\%CI=168-267), representing 31 weeks.

Progression-free survival (defined by time to radiological progress) was 141 days (95\% CI=96-185) (20 weeks). Overall survival from start of treatment was 218 days $(95 \%$ $\mathrm{CI}=168-267$ ) (31 weeks) (Figure 1). Total overall survival from diagnosis until death in this cohort was 1.6 years (Figure 2). In general, treatment was well tolerated but 9\% (6 of 64) of the patients suffered from serious complications (one patient had an intracerebral bleeding, one patient suffered from pulmonary embolisation, two patients had deep venous thrombosis, one patient had a lethal gastrointestinal perforation and one patient died from sepsis). When measuring contrast-enhanced tumour volume before start of treatment with bevacizumab and at best response, 30 patients out of $44(68 \%)$ had a tumour volume reduction from baseline exceeding 25\% (Figure 3).

\section{Discussion}

The present retrospective study indicates a clinically significant effect of bevacizumab-based chemotherapy in the second-line setting for high-grade glioma. Response rate of $68 \%$ and a PFS of 20 weeks is comparable to previously reports from controlled clinical trials and motivates randomized controlled trials in the second line setting.

Bevacizumab was approved in 2009 , by the U.S. Food and Drug Administration (FDA) for recurrent glioblastoma based on imaging and clinical responses demonstrated in two phase II clinical trials; The BRAIN study (AVF3708g) randomised 167 patients with progressive disease after primary

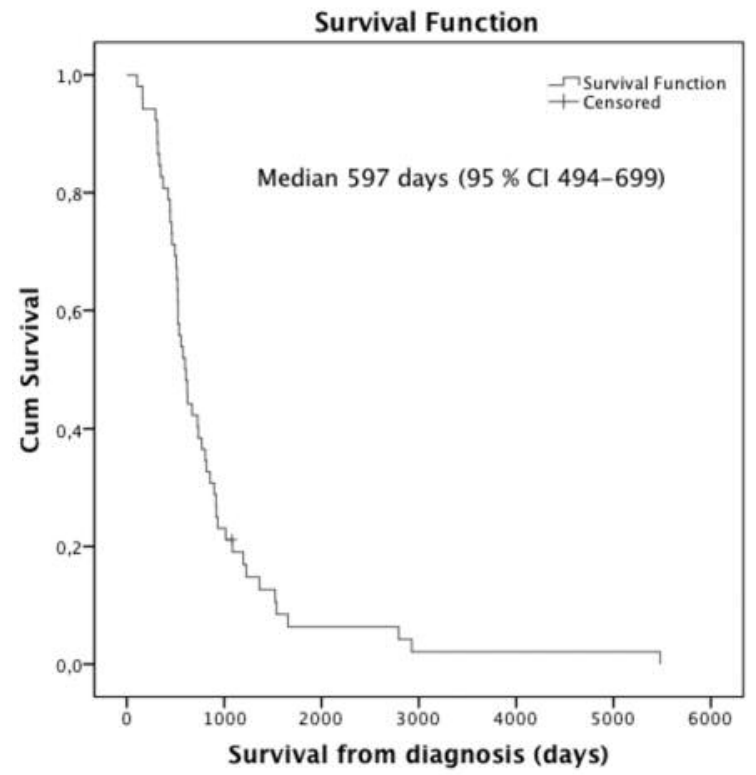

Figure 2. Overall survival from diagnosis to death in all patients treated with bevacizumab for progressive malignant glioma, representing 1.6 years (median=597 days).

treatment, between combination therapy with bevacizumab and irinotecan and bevacizumab monotherapy. This study showed an objective response of $28 \%$ and $38 \%$, respectively. The median overall response duration was 9.2 and 8.7 months, respectively (10). In the NCI 06-C-0064E-study, 48 


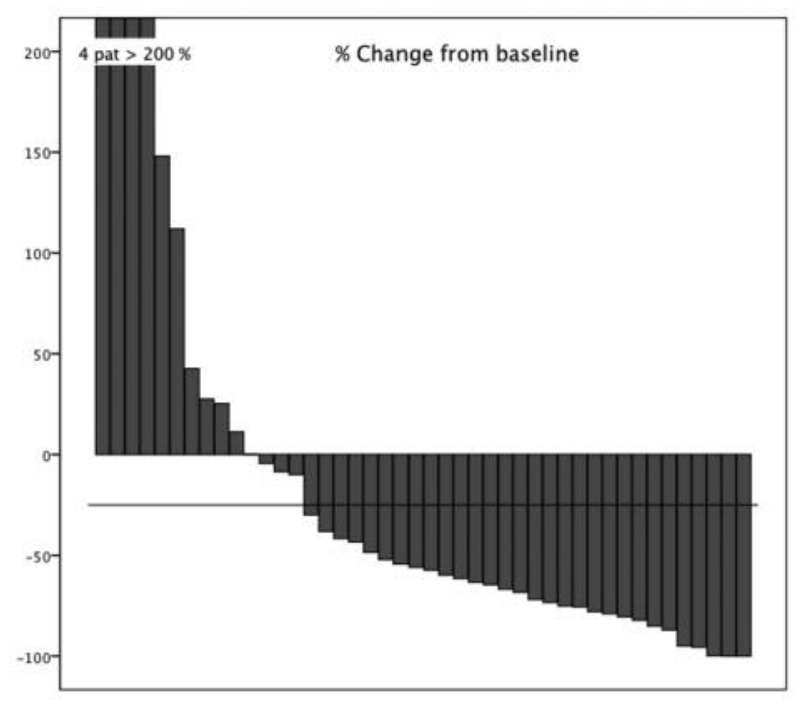

Figure 3. Waterfall plot of best radiographic response for the 44 evaluable patients. Horizontal line represents $-25 \%$ change in tumour volume from baseline.

patients with recurrent malignant glioma were treated with bevacizumab monotherapy until progression, followed by bevacizumab in combination with irinotecan. The conclusion was that bevacizumab as a single-agent has a significant biologic effect in patients with progressive glioblastoma (11). Based on the same studies, the European Medicines Agency (EMA) denied approval of bevacizumab for this diagnosis. The main arguments for the decision were absence of control arms, inadequate response criteria and difficulties in interpreting outcome. Bevacizumab in combination with irinotecan was therefore not introduced as a routine second line treatment in most European countries while the combination gained widespread use in the USA. Further clinical development was focussed on the first line setting.

In the first-line setting, data from two phase III studies are published; the AVAglio-study (12) which randomised 921 patients between bevacizumab or placebo in addition to radiochemotherapy in newly diagnosed glioblastoma and RTOG 0825 (NCT00884741) (13), which randomised 637 patients between those treatments starting week 4 of radiochemotherapy. These two studies had two co-primary endpoints (PFS and OS) and did not meet the endpoint with prolonged overall survival but showed an improved median progression free survival in the bevacizumab arms with a median of 4.4 and 3.7 months respectively. In the AVAglio study quality of life was maintained for the patients treated with bevacizumab compared to placebo while in the RTOG 0825 -study a deterioration in quality of life and a decline in neurocognitive function were seen in the group receiving bevacizumab. These two studies aimed to answer the question
Table II. Comparable studies.

\begin{tabular}{lcccc}
\hline & $\begin{array}{c}\text { Vredenburgh } \\
2007\end{array}$ & $\begin{array}{c}\text { Norden } \\
2008\end{array}$ & $\begin{array}{c}\text { Poulsen } \\
2009\end{array}$ & $\begin{array}{c}\text { Sandström } \\
2017\end{array}$ \\
\hline Number of patients & 35 & 55 & 52 & 52 \\
PFS (weeks) & 24 & 24 & 22 & 20 \\
OS (weeks) & 42 & 36 & 30 & 31 \\
\hline
\end{tabular}

if bevacizumab is of value in the first-line setting when combined with radiotherapy and temozolomide. Results of the studies indicate an activity of bevacizumab in the firstline setting but due to the conflicting results and no OS improvement bevacizumab is not yet approved in the first line setting. Recently, patients included in the AVAglio-study were retrospective evaluated and an OS-benefit is now suggested for patients with isocitrate dehydrogenase 1 (IDH1) wild-type tumours (14). The randomized phase II GLARIUS study, showed that treatment with bevacizumab/ irinotecan appears superior to TMZ for patients with MGMT-unmethylated glioblastoma both regarding PFS-6 and median PFS in the first line setting. Treatment with bevacizumab/irinotecan did not improve OS, but there was a high grade of cross-over where patients in the TMZ-arm was treated with bevacizumab/irinotecan at progression (15).

In the Dutch randomized phase II study BELOB, patients with recurrent glioblastoma were randomised to either one of three treatment-arms; bevacizumab plus lomustine, bevacizumab or lomustine. This study shows a possible synergistic effect on median OS and PFS when combining bevacizumab with lomustine (9). In our retrospective study, where treatment with bevacizumab-based chemotherapy was offered to patients with progressive malignant glioma, we obtained comparable results to those reported in the literature with a median overall survival of 31 weeks after initiation of treatment (Table II). Treatment with radiochemotherapy after surgery is standard for patients with glioblastoma. In this study 10 patients with grade III tumours were treated equally as grade IV. The reason for this is that all 10 patients had been clinically and/or radiologically evaluated as more malignant than grade III, resembling more a grade IV tumour. Since the study is retrospective and not randomised, we need to compare our outcomes with historic controls reported in the literature. In a study from the year 2000, patients with first recurrence of disease were randomised between temozolomide and procarbazine. In this study median PFS was 12.4 weeks for the group receiving temozolomide (16). Total overall survival from diagnosis in our clinical cohort is 1.6 years (19.9 months). Compared to a clinical material from the Swedish quality registry for patients with malignant glioma in a cohort collected between 2004-2006 (before bevacizumab was used in second 
line), median overall survival was 8.5 months exceeding median survival in the group of patients in the age between 60 and 69 years by 11.4 months (3). The outcome in our series of patients is comparable to previous reports. A high proportion of patients in our study had a radiographic response. This was often in accordance with clinical outcome, which contradicts the theory that radiographic regression represents a pseudoregression only caused by a normalisation of the vessel bed, thereby hiding the growing tumour since normalisation of vessels inhibits contrast enhancement. Our impression is also that most recurrences were local and not diffuse or distant, as was anticipated when anti-angiogenic treatment was first introduced for brain tumours. The rationale for this concern is that the molecular mechanisms of angiogenesis and invasiveness are similar (PI3K/mTOR-pathway) and that VEGF inhibition in pre-clinical studies promotes invasiveness $(17,18)$. However, follow-up analyses of clinical series does not support a specific propensity of bevacizumab to induce diffuse growth or distant spread at recurrence (19).

Treatment options today for patients with progressive highgrade malignant glioma are few. In our Institution we are offering treatment with bevacizumab in combination with irinotecan or TMZ to patients with progressive malignant glioma since 2007. We find this treatment to be tolerable and active and it has been used due to lack of alternative options for patients with progressive malignant glioma. A weakness in this study is its retrospective design in which a certain risk for selection bias where only patients in good performance status are treated with bevacizumab; on the other hand we have also treated patients in performance status 3 , reflecting a clinical representative group of patients. From a statistical point of view the study is limited due to a relative small number of patients. The BELOB-study now indicates that bevacizumab in combination with CCNU (lomustine) is superior to bevacizumab and CCNU monotherapy. This study, therefore, supports the use of an additional and more rational combination with bevacizumab as second-line therapy. A phase III trial on the combination of lomustine and bevacizumab is ongoing by EORTC (study 26101, NCT01290939). Another single-center study from 2016, the SV1-study, also support our findings with similar results where median PFS was 26 weeks and median OS was 28 weeks (20).

In this retrospective single-Institution study, we report comparable results using bevacizumab in the second-line setting, as those reported in the literature. We found that bevacizumab is active for malignant glioma with response rates of $68 \%$. Randomized clinical studies in the second-line setting are, therefore, still clearly encouraged.

\section{Conflicts of Interest}

Mikael Johansson has received lecture fees from Roche Sweden AB during the study period. No other conflicts of interest exist.

\section{Acknowledgements}

Ove Björ is acknowledged for invaluable statistical advice. The Authors are also grateful for financial support from the Cancer Research Foundation in Northern Sweden. Further financial support was provided through regional agreement between Umeå University and Västerbotten County Council on cooperation in the field of Medicine, Odontology and Health (ALF).

\section{References}

1 Stupp R, Mason WP, van den Bent MJ, Weller M, Fisher B, Taphoorn MJB, Belanger K, Brandes AA, Marosi C, Bogdahn U, Curschmann J, Janzer RC, Ludwin SK, Gorlia T, Allgeier A, Lacombe D, Cairncross JG, Eisenhauer E, Mirimanoff RO, European Organisation for Research and Treatment of Cancer Brain Tumor and Radiotherapy Groups National Cancer Institute of Canada Clinical Trials Group: Radiotherapy plus concomitant and adjuvant temozolomide for glioblastoma. N Engl J Med 352: 987-996, 2005.

2 Stupp R, Hegi ME, Mason WP, van den Bent MJ, Taphoorn MJ, Janzer RC, Ludwin SK, Allgeier A, Fisher B, Belanger K, Hau P, Brandes AA, Gijtenbeek J, Marosi C, Vecht CJ, Mokhtari K, Wesseling P, Villa S, Eisenhauer E, Gorlia T, Weller M, Lacombe D, Cairncross JG, Mirimanoff R-O, Groups OBOTEOFRATOCBTARO the National Cancer Institute of Canada Clinical Trials Group: Articles Effects of radiotherapy with concomitant and adjuvant temozolomide versus radiotherapy alone on survival in glioblastoma in a randomised phase III study: 5-year analysis of the EORTC-NCIC trial. Lancet Oncology 10: 459-466, 2009.

3 Asklund T, Malmström A, Björ O, Blomquist E and Henriksson $\mathrm{R}$ : Considerable improvement in survival for patients aged 6084 years with high grade malignant gliomas - data from the Swedish brain tumour population-based registry. Acta Oncol 52: 1041-1043, 2013.

4 Plate KH, Scholz A and Dumont DJ: Tumor angiogenesis and anti-angiogenic therapy in malignant gliomas revisited. Acta Neuropathol 124: 763-775, 2012.

5 Vredenburgh JJ, Desjardins A, Herndon JE, Marcello J, Reardon DA, Quinn JA, Rich JN, Sathornsumetee S, Gururangan S, Sampson J, Wagner M, Bailey L, Bigner DD, Friedman AH and Friedman H: Bevacizumab plus irinotecan in recurrent glioblastoma multiforme. J Clin Oncol 25: 4722-4729, 2007.

6 Henriksson R, Asklund T and Poulsen HS: Impact of therapy on quality of life, neurocognitive function and their correlates in glioblastoma multiforme: a review. J Neurooncol 104: 639-646, 2011.

7 Nagpal S, Harsh G and Recht L: Bevacizumab improves quality of life in patients with recurrent glioblastoma. Chemotherapy Research and Practice 2011: 1-6, 2011.

8 Hofer S, Elandt K, Greil R, Hottinger AF, Huber U, Lemke D, Marosi C, Ochsenbein A, Pichler J, Roelcke U, Weder P, Zander T, Wick W and Weller M: Clinical outcome with bevacizumab in patients with recurrent high-grade glioma treated outside clinical trials. Acta Oncol 50: 630-635, 2011.

9 Taal W, Oosterkamp HM, Walenkamp AME, Dubbink HJ, Beerepoot LV, Hanse MCJ, Buter J, Honkoop AH, Boerman D, de Vos FYF, Dinjens WNM, Enting RH, Taphoorn MJB, van den Berkmortel FWPJ, Jansen RLH, Brandsma D, Bromberg JEC, 
van Heuvel I, Vernhout RM, van der Holt B and van den Bent MJ: Single-agent bevacizumab or lomustine versus a combination of bevacizumab plus lomustine in patients with recurrent glioblastoma (BELOB trial): a randomised controlled phase 2 trial. Lancet Oncology 15: 943-953, 2014.

10 Friedman H, Prados MD, Wen PY, Mikkelsen T, Schiff D, Abrey LE, Yung WKA, Paleologos N, Nicholas MK, Jensen R, Vredenburgh $\mathrm{J}$, Huang $\mathrm{J}$, Zheng $\mathrm{M}$ and Cloughesy $\mathrm{T}$ : Bevacizumab alone and in combination with irinotecan in recurrent glioblastoma. J Clin Oncol 27: 4733-4740, 2009.

11 Kreisl TN, Kim L, Moore K, Duic P, Royce C, Stroud I, Garren N, Mackey M, Butman JA, Camphausen K, Park J, Albert PS and Fine HA: Phase II trial of single-agent bevacizumab followed by bevacizumab plus irinotecan at tumor progression in recurrent glioblastoma. J Clin Oncol 27: 740-745, 2009.

12 Chinot OL, Wick W, Mason W, Henriksson R, Saran F, Nishikawa R, Carpentier AF, Hoang-Xuan K, Kavan P, Cernea $\mathrm{D}$, Brandes AA, Hilton M, Abrey $\mathrm{L}$ and Cloughesy $\mathrm{T}$ : Bevacizumab plus radiotherapy-temozolomide for newly diagnosed glioblastoma. N Engl J Med 370: 709-722, 2014.

13 Gilbert MR, Dignam JJ, Armstrong TS, Wefel JS, Blumenthal DT, Vogelbaum MA, Colman H, Chakravarti A, Pugh S, Won M, Jeraj R, Brown PD, Jaeckle KA, Schiff D, Stieber VW, Brachman DG, Werner-Wasik M, Tremont-Lukats IW, Sulman EP, Aldape KD, Curran WJ Jr. and Mehta MP: A randomized trial of bevacizumab for newly diagnosed glioblastoma. N Engl J Med 370: 699-708, 2014.

14 Sandmann T, Bourgon R, Garcia J, Li C, Cloughesy T, Chinot OL, Wick W, Nishikawa R, Mason W, Henriksson R, Saran F, Lai A, Moore N, Kharbanda S, Peale F, Hegde P, Abrey LE, Phillips HS and Bais C: Patients with proneural glioblastoma may derive overall survival benefit from the addition of bevacizumab to first-line radiotherapy and temozolomide: retrospective analysis of the AVAglio trial. J Clin Oncol 33: 2735-2744, 2015.

15 Herrlinger U, Schäfer N, Steinbach JP, Weyerbrock A, Hau P, Goldbrunner R, Friedrich F, Rohde V, Ringel F, Schlegel U, Sabel M, Ronellenfitsch MW, Uhl M, Maciaczyk J, Grau S, Schnell O, Hänel M, Krex D, Vajkoczy P, Gerlach R, Kortmann R-D, Mehdorn M, Tüttenberg J, Mayer-Steinacker R, Fietkau R,
Brehmer S, Mack F, Stuplich M, Kebir S, Kohnen R, Dunkl E, Leutgeb B, Proescholdt M, Pietsch T, Urbach H, Belka C, Stummer W and Glas M: Bevacizumab plus irinotecan versus temozolomide in newly diagnosed $\mathrm{O}^{6}$-methylguanine-DNA methyltransferase nonmethylated glioblastoma: the randomized GLARIUS Trial. J Clin Oncol 34: 1611-1619, 2016.

16 Friedman H, Yung WK, Albright RE, Olson J, Fredericks R, Fink K, Prados MD, Brada M, Spence A, Hohl RJ, Shapiro W, Glantz M, Greenberg H, Selker RG, Vick NA, Rampling R, Phillips P, Bruner J, Yue N, Osoba D, Zaknoen S and Levin VA: A phase II study of temozolomide $v s$. procarbazine in patients with glioblastoma multiforme at first relapse. Br J Cancer 83: 588-593, 2000

17 Pàez-Ribes M, Allen E, Hudock J, Takeda T, Okuyama H, Viñals $\mathrm{F}$, Inoue $\mathrm{M}$, Bergers $\mathrm{G}$, Hanahan $\mathrm{D}$ and Casanovas $\mathrm{O}$ : Antiangiogenic therapy elicits malignant progression of tumors to increased local invasion and distant metastasis. Cancer Cell 15: 220-231, 2009.

18 Keunen O, Johansson M, Oudin A, Sanzey M, Rahim SAA, Fack F, Thorsen F, Taxt T, Bartos M, Jirik R, Miletic H, Wang J, Stieber D, Stuhr L, Moen I, Rygh CB, Bjerkvig R and Niclou SP: Anti-VEGF treatment reduces blood supply and increases tumor cell invasion in glioblastoma. Proc Natl Acad Sci USA 108: 3749-3754, 2011.

19 Wick W, Wick A, Weiler $M$ and Weller M: Patterns of progression in malignant glioma following anti-VEGF therapy: perceptions and evidence. Curr Neurol Neurosci Rep 11: 305312, 2011.

20 Rivoirard R, Chargari C, Guy J-B, Nuti C, Peoc'h M, Forest F, Falk AT, Garin C, Adjabi A, Hoarau D, Fotso M-J, Langrand Escure J, Moriceau G, Fournel P, Boutet C and Magné N: Clinical impact of bevacizumab in patients with relapsed glioblastoma: focus on a real-life monocentric SurVey (SV1 Study). Chemotherapy 61: 269-274, 2016.

Received January 31, 2017

Revised March 3, 2017

Accepted March 6, 2017 